Article

\title{
Catalytic Activities of Multimeric G-Quadruplex DNAzymes
}

\author{
Raphael I. Adeoye ${ }^{1}$, Dunsin S. Osalaye ${ }^{1}$, Theresia K. Ralebitso-Senior ${ }^{2}{ }^{(1)}$, Amanda Boddis ${ }^{2}$, \\ Amanda J. Reid ${ }^{2}$, Amos A. Fatokun ${ }^{2}$ (D), Andrew K. Powell ${ }^{2}$, Sylvia O. Malomo ${ }^{1}$ and \\ Femi J. Olorunniji $2, *$ (D) \\ 1 Department of Biochemistry, University of Ilorin, Ilorin 240003, Kwara State, Nigeria \\ 2 School of Pharmacy and Biomolecular Sciences, Faculty of Science, Liverpool John Moores University, \\ Liverpool L3 3AF, UK \\ * Correspondence: F.J.Olorunniji@ljmu.ac.uk; Tel.: +44-0151-231-2116
}

Received: 9 July 2019; Accepted: 15 July 2019; Published: 19 July 2019

\begin{abstract}
G-quadruplex DNAzymes are short DNA aptamers with repeating G4 quartets bound in a non-covalent complex with hemin. These G4/Hemin structures exhibit versatile peroxidase-like catalytic activity with a wide range of potential applications in biosensing and biotechnology. Current efforts are aimed at gaining a better understanding of the molecular mechanism of DNAzyme catalysis as well as devising strategies for improving their catalytic efficiency. Multimerisation of discrete units of G-quadruplexes to form multivalent DNAzyes is an emerging design strategy aimed at enhancing the peroxidase activities of DNAzymes. While this approach holds promise of generating more active multivalent G-quadruplex DNAzymes, few examples have been studied and it is not clear what factors determine the enhancement of catalytic activities of multimeric DNAzymes. In this study, we report the design and characterisation of multimers of five G-quadruplex sequences (AS1411, Bcl-2, c-MYC, PS5.M and PS2.M). Our results show that multimerisation of G-quadruplexes that form parallel structure (AS1411, Bcl-2, c-MYC) leads to significant rate enhancements characteristic of cooperative and/or synergistic interactions between the monomeric units. In contrast, multimerisation of DNA sequences that form non-parallel structures (PS5.M and PS2.M) did not exhibit similar levels of synergistic increase in activities. These results show that design of multivalent G4/Hemin structures could lead to a new set of versatile and efficient DNAzymes with enhanced capacity to catalyse peroxidase-mimic reactions.
\end{abstract}

Keywords: G-quadruplex; DNAzymes; peroxidase; multimers; synergism

\section{Introduction}

Haem peroxidases use protein scaffolds that activate haem to react with $\mathrm{H}_{2} \mathrm{O}_{2}$ [1]. The reaction mechanism and properties of peroxidases have been extensively studied and they have several practical uses in research, bioanalysis and industrial applications. More recently, it was discovered that certain DNA aptamers have the ability to catalyse reactions similar to those carried out by haem peroxidases [2,3]. These DNA aptamers are Guanine-rich DNA oligonucleotides that form complexes with hemin to form G-quadruplexes (often referred to as G4/Hemin) with catalytic activities that mimic peroxidases [4-6]. The oligonucleotide sequences that form G-quartets are organised into G-quadruplexes in the presence of cations to form high-affinity binding sites for hemin turning these nanostructures into powerful catalysts that activate $\mathrm{H}_{2} \mathrm{O}_{2}$ for peroxidase-like oxidation reactions (Figure 1). These complexes (often referred to as DNAzymes) are more stable to extreme reaction conditions than protein enzymes, and are easier to synthesise and modify via chemical processes. 


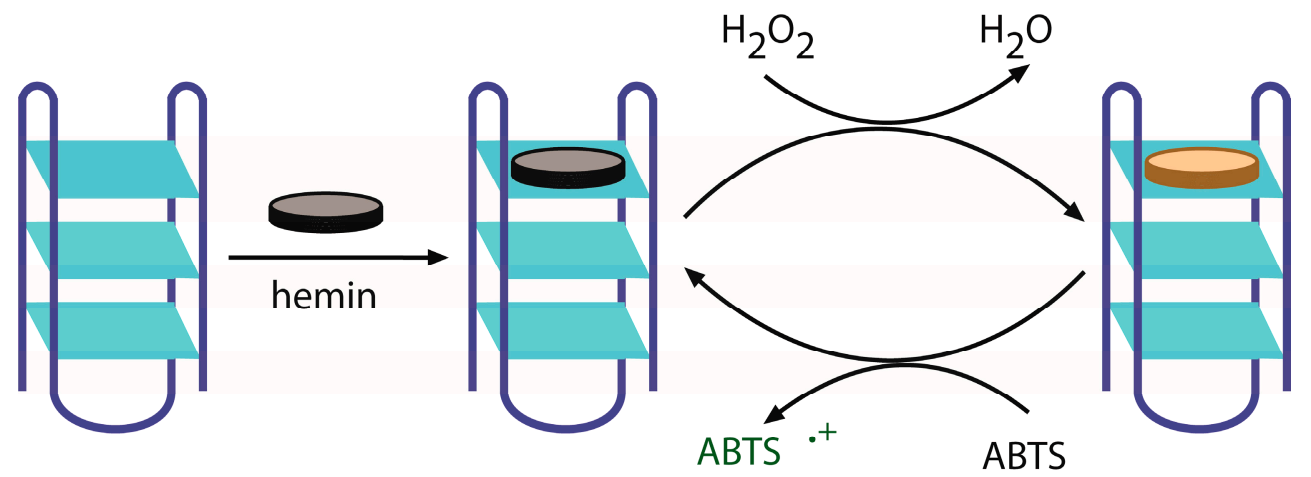

Figure 1. Assembly of G-quadruplex-hemin DNAzymes and $\mathrm{H}_{2} \mathrm{O}_{2}$-activated oxidation of ABTS. Guanine-rich DNA oligonucleotides fold to form G-quartet interactions (blue planes) which bind to hemin (grey discs). The resulting DNAzyme complex activates $\mathrm{H}_{2} \mathrm{O}_{2}$ to oxidise a donor substrate (in this instance ABTS) using a mechanism similar to haem peroxidase-catalysed reactions. The reduced haem (brown disc) can react with $\mathrm{H}_{2} \mathrm{O}_{2}$ and initiate another round of ABTS oxidation. The reaction product $\left(\mathrm{ABTS}^{\bullet}\right.$ ) has a bright green colour with absorption maximum around $412-422 \mathrm{~nm}$.

G-quadruplex DNAzymes have the potential for development as nanodevices for applications in biosensors, diagnostics, and bioremediation and other aspects of biotechnology [7,8]. However, their relatively low catalytic activity in comparison to protein peroxidases currently restricts further development and applications of these systems. In order to develop DNAzymes into useful applications, it is necessary to characterize the structural and functional sequence parameters that influence the efficiency of DNAzyme reactions and their functionalities in applied devices.

Several strategies are being explored to improve the catalytic efficiency and reaction properties of peroxidase G-quadruplex DNAzymes [8]. One such approach is the finding that addition of polycationic amines such as spermine, spermidine, and putrescine significantly increases the activities of DNAzymes by favouring catalytically active conformations [9-11]. Similar rate-enhancements were observed by the addition of the nucleotide ATP to DNAzyme reactions [12,13]. It has also been reported that the conjugation of hemin with the G4-quadruplex moiety via covalent linkage [14] or with cationic peptides [15] can enhance the activities of DNAzymes. Other studies have focused on the rate-enhancing effects of flanking adenine or cytosine nucleotides on G-quadruplex activities [16-19].

Multimerisation of discrete units of G-quadruplexes to form multivalent DNAzymes is an emerging design strategy aimed at enhancing the peroxidase activities of DNAzymes [20,21]. In these multiple active site structures, individual DNAzyme molecular units are joined together by polynucleotide linkers that do not participate directly in the reactions. Some studies show that the linker length between individual DNAzyme molecules can be a determining factor in the activities of multimeric DNAzymes [17,19]. It is thought that this rate enhancement results from synergistic interactions between the individual subunits. In these arrangements, a multivalent DNAzyme sequence would be more active than the sum activities of an equal number of monomeric sequence units [20,21]. One hypothesis that explains the rate-enhancing effect of mulitimerisation is that multimeric DNAzyme structures potentially create additional high-affinity binding sites for haem incorporation, thereby resulting in more than one active site per DNAzyme monomer. However, in certain cases, there is no direct correlation between the number of units and the activity of the multimer [20,21]. This suggests that certain structural features do not necessarily support activity enhancement in multimers. Gaining a good understanding of the properties of such multivalent G-quadruplex DNAzymes would provide more insight into strategies for rational design of highly active DNAzymes.

While multimerisation has the potential to generate more active DNAzymes, only a handful of DNAzyme multimers have been reported [20-22]. It is not entirely clear what factors determine the catalytic properties of multimers when compared to their monomeric G-quadruplexes. For example, several key questions remained unanswered. Does multimerisation lead to cooperative and synergistic 
rate enhancement of activity in all G-quadruplexes that exhibit peroxidase activities? Is there a direct correlation between the number of monomer subunits and catalytic efficiency? Do certain multimeric combinations result in limited rate enhancement or potential inhibition of catalytic activity? Does the number of G-quartets in a G-quadruplex aptamer determine catalytic efficiency? Can contiguous multimerisation result in a redistribution of catalytic units or generation of high-activity pockets?

In an effort to understand these questions, we started by designing dimers and trimers of selected DNAzymes in order to study their catalytic properties in detail. In this report, we describe the activities of multimers of five different DNAzymes with their corresponding monomers. Using the dinucleotide TT as the linker sequence, we made dimers and trimers of AS1411, also known as AGRO100 [23], Bcl-2 [11,24], c-MYC [11], PS5.M and PS2.M [23]. Using the standard $\mathrm{H}_{2} \mathrm{O}_{2} /$ ABTS oxidation assay, we determined the effects of multimerisation on five G-quadruplex DNAzymes. Our findings indicate that multivalency results in synergistic rate enhancements for some DNAzyme sequences, while multimers of certain aptamers resulted in reduced activity per haem binding site.

\section{Results and Discussion}

\subsection{Design of Multimeric DNAzymes}

To study the properties of multimeric G-quadruplex DNAzymes, we selected five different DNAzyme sequences (Table 1) that have been described in the literature. We selected AS1411, a highly-active DNAzyme [11,23] that is also reported as an anti-cancer agent owing to its ability to target the protein nucleolin which is highly expressed on the surface of cancer cells [25]. PS5.M and its sequence-derivative PS2.M [3] were also chosen for their high activities. In addition, this group of DNAzymes has been extensively studied and reported in the literature [26].

Table 1. Sequences of DNAzymes used in this study. The DNA sequences are written in $5^{\prime}$ to $3^{\prime}$ direction.

\begin{tabular}{cc}
\hline DNAzyme & Sequence \\
\hline AS1411 & GGTGGTGGTGGTTGTGGTGGTGGTGG \\
Bcl-2 & GGGCGCGGGAGGAAGGGGGCGGG \\
c-MYC & GAGGGTGGGGAGGGTGGGGAAG \\
PS5.M & GTGGGTCATTGTGGGTGGGTGTGG \\
PS2.M & GTGGGTAGGGCGGGTTGG \\
\hline
\end{tabular}

c-MYC and Bcl-2 are less-characterised DNAzymes in comparison to the three described above. The assumption is that these low-activity DNAzymes would be an ideal model system to test any potential rate enhancement due to G-quadruplex multimerisation. c-MYC is derived from a G-rich region in the promoter sequence of the human $c$-myc gene [27], while Bcl-2 was identified as a G-rich segment of the Bcl-2 P1 promoter and shown to form mixed intramolecular G-quadruplex structures [28,29].

In each case, the multimers (dimers and trimers) were made by joining the nucleotide at the $3^{\prime}$ end of the DNAzyme sequence to the one on the $5^{\prime}$ end of the same sequence using a TT dinucleotide linker (Figure 2F). It is known that the identity of the base composition and length of the linker sequence can influence the activities of monovalent and multivalent DNAzymes [17]. To remove the potential for linker-dependent effects on our analyses, we chose to use the relatively simple TT linker sequence in order to obtain a relatively unconfounded effect of multimerisation on DNAzyme activity [20,21]. 

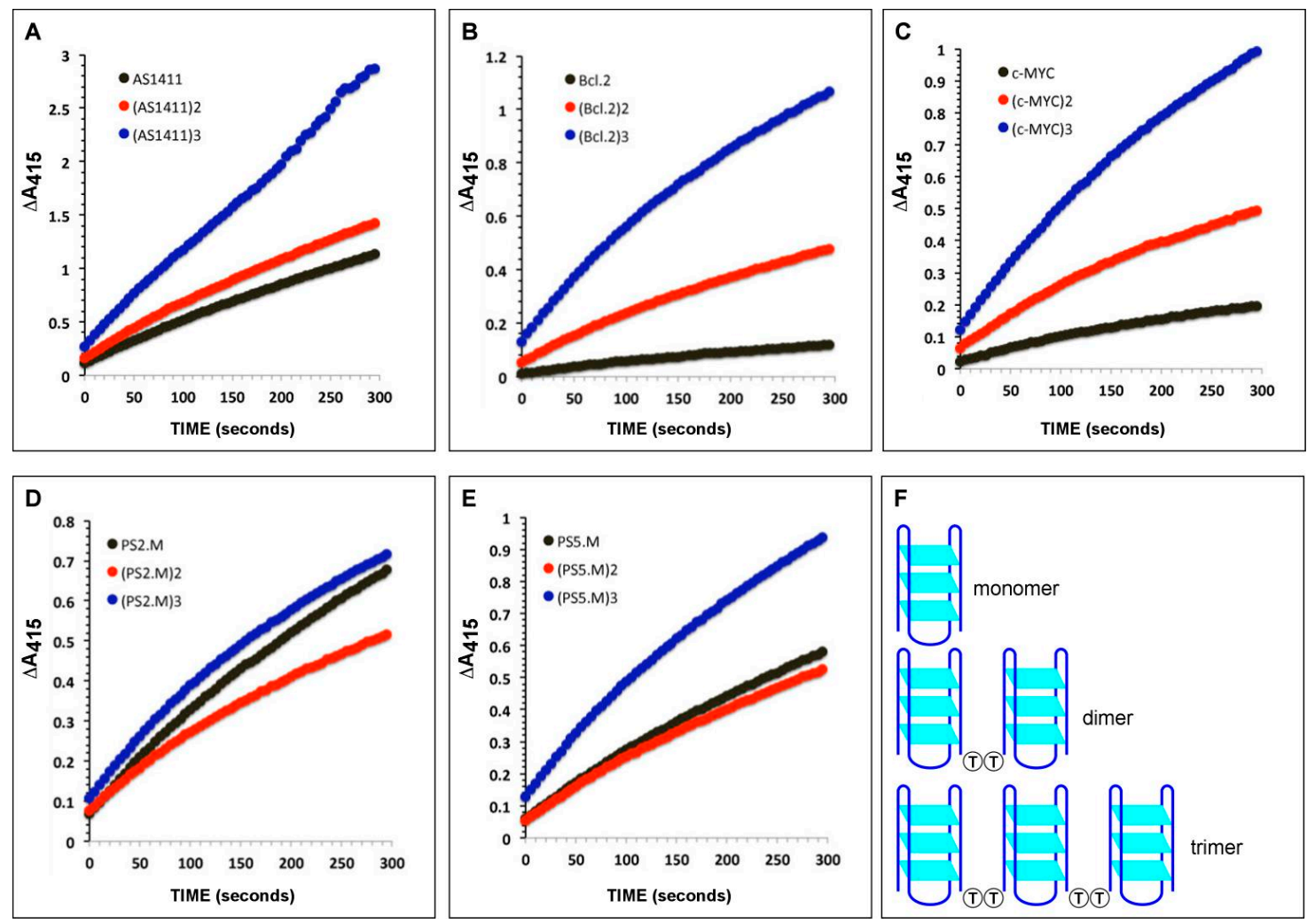

Figure 2. Time course of DNAzyme-catalysed reaction between $\mathrm{H}_{2} \mathrm{O}_{2}$ and ABTS (A) AS1411 and multimers; (B) Bcl-2 and multimers; (C) c-MYC and multimers; (D) PS5.M and multimers, (E) PS2.M and multimers. The numerals 2 and 3 behind each DNAzyme name refer to dimer and trimer respectively e.g., (AS1411)2 and (AS1411)3. Reactions were carried out in $25 \mathrm{mM} \mathrm{HEPES-NaOH} \mathrm{pH} \mathrm{7.4,} 20 \mathrm{mM}$ $\mathrm{KCl}, 200 \mathrm{mM} \mathrm{NaCl}, 0.05 \%$ Triton X-100, 1\% DMSO. The activities of $0.25 \mu \mathrm{M}$ DNAzyme were assayed using ABTS $(2.5 \mathrm{mM})$ and $\mathrm{H}_{2} \mathrm{O}_{2}(0.425 \mathrm{mM})$. Each reaction was started by the addition of $\mathrm{H}_{2} \mathrm{O}_{2}$, and change in $\mathrm{A}_{415}$ was monitored immediately after starting the reaction for $5 \mathrm{~min}$. The absorbance values shown were zeroed with those obtained in reactions that did not include the DNAzyme. Each trace is representative of three different reactions. (F) Schematic illustration of the design of G-quadruplex DNAzyme dimers and trimers. In the multimers, each monomeric unit is joined to the next by a TT dinucleotide.

\subsection{Catalytic Activities of DNAzymes}

Several buffer systems have been used to assay the activities of G4/Hemin DNAzymes, and it is clear that the reaction buffer $\mathrm{pH}$ as well as its composition play important role in the reaction rate and the stability of the product radical [3]. A common issue in peroxidation reactions is disproportionation of the reaction product [13], with certain buffers supporting the stability of the reaction product more than others. We used $25 \mathrm{mM}$ HEPES-NaOH, pH 7.4, as the reaction buffer in these experiments since this buffer system supports both the actual peroxidase reaction as well as stability of the product $[3,13,23,30]$.

All the 15 G-quadruplexes tested in this study displayed ABTS oxidation activities (Figure 2) and preliminary assays showed that a linear relationship exists between the concentration of G-quadruplex DNAzymes and peroxidase activities. In all cases, initial rates of ABTS oxidation increased linearly with DNAzyme concentration providing the concentrations of the substrates ABTS and $\mathrm{H}_{2} \mathrm{O}_{2}$ are not limiting (Figure 2).

AS1411: Consistently, AS1411 performed better in the reaction conditions used here than the other 4 DNAzymes tested. Similar high activities for AS1411 have been reported [23]. Their initial rate measurements showed that AS1411 is about 1.5-fold more active than PS5.M, and 2-fold more active than PS2.M. Our results generally agree with these measurements, both in initial rate and turnover 
numbers (Figure 3). Initial rate measurements showed that the multimeric forms of AS1411 were more active than the monomer. While there was a slight increase in the activity of the dimer $(819 \mathrm{nM} / \mathrm{s})$ over the monomer $(639 \mathrm{nM} / \mathrm{s})$, a more remarkable effect was seen in the activity of the trimer $(1472 \mathrm{nM} / \mathrm{s})$. Similar trends were seen in the amount of ABTS ${ }^{\bullet}$ radical formed after 5 min of reaction (Figure 3B).
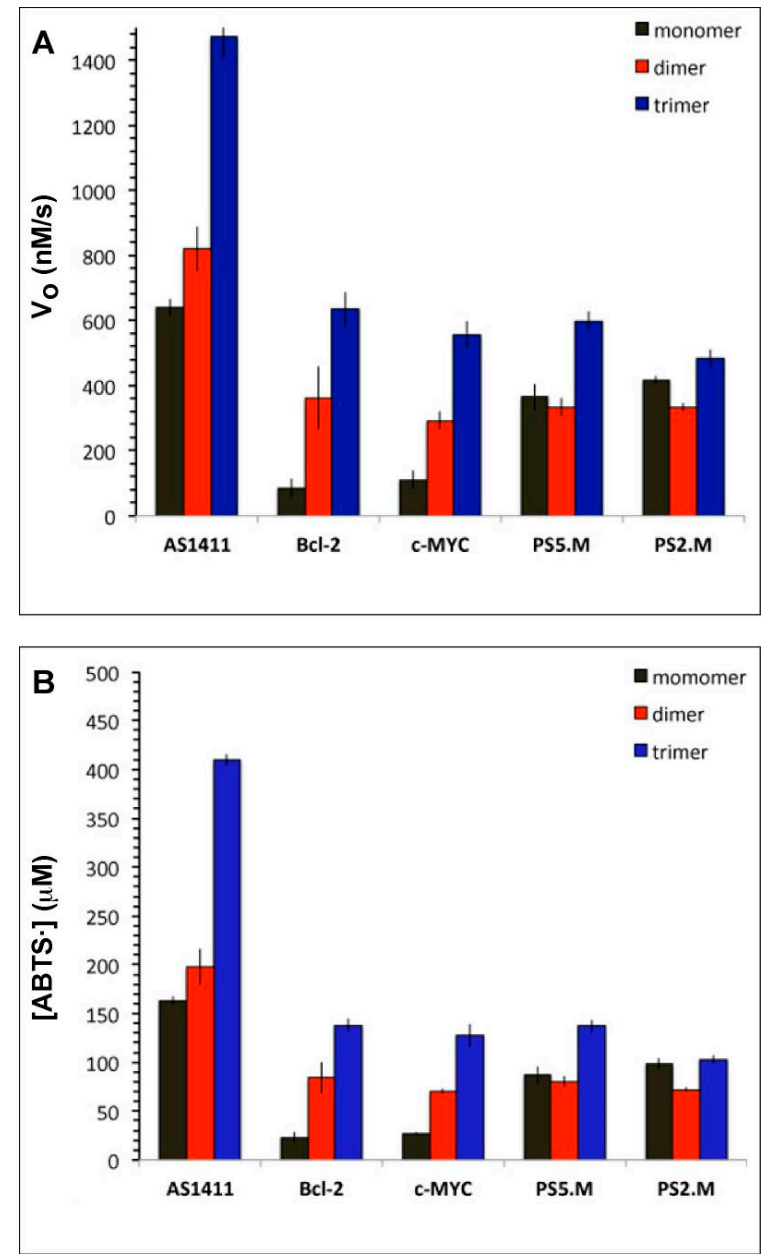

Figure 3. DNAzyme activities of DNAzymes. (A) Initial Rates (expressed as $\mathrm{V}_{\mathrm{o}}, \mathrm{nM} / \mathrm{s}$ ) were calculated from the slope of the initial linear portion (typically, the first $30 \mathrm{~s}$ ) of the reaction curves shown in Figure 2. (B) The amount of ABTS ${ }^{\bullet}$ radical produced after $300 \mathrm{~s}$ from the activity of $1 \mu \mathrm{M}$ DNAzyme were determined from the endpoint of the reaction time course shown in Figure 2. See Materials and Methods.

Bcl-2: In comparison to AS1411, Bcl-2 is a relatively low activity DNAzyme [11,24]. As shown in Figure $2 \mathrm{~B}$, multimerisation had a remarkable rate-enhancing effect on Bcl-2 activity. The initial rate measurements (monomer, $83 \mathrm{nM} / \mathrm{s}$; dimer, $360 \mathrm{nM} / \mathrm{s}$; trimer, $634 \mathrm{nM} / \mathrm{s}$ ) showed a 4-fold enhancement effect from dimerisation and nearly 8 -fold from trimerisation (Figure 3A). Similar trends were observed in the total amount of $\mathrm{ABTS}^{\bullet}$ product formed (Figure 3B).

c-MYC: In a pattern similar to that seen with Bcl-2, multimerisation significantly enhanced the ABTS oxidation activity of c-MYC. (Figure 2C). The initial rate measurements obtained were monomer $(111 \mathrm{nM} / \mathrm{s})$, dimer $(291 \mathrm{nM} / \mathrm{s})$, and trimer $(556 \mathrm{nM} / \mathrm{s})$. The amount of product formed showed a similar trend (Figure 3). These values represent approximately 3- and 5-fold increases as a result of dimerisation and trimerisation, respectively.

PS5.M and PS2.M: PS5.M and PS2.M are two of the best-studied peroxidase DNAzymes and have been used as model systems for characterising aspects of G-quadruplex DNAzymes catalytic 
mechanism. Indeed, PS5.M is one of the first DNA oligonucleotide aptamers shown to have the ability to bind hemin and acquire peroxidatic catalytic activities [2,3]. The 18-nucleotide PS2.M was derived from rational redesign of the 24-nucleotide PS5.M to achieve better catalytic activity [3]. In our experiments, the activity of PS2.M (416 nM/s) (Figure 2D,E) was higher than that of PS5.M ( $364 \mathrm{nM} / \mathrm{s})$ (Figure 3A).

In contrast to the DNAzymes described above (AS1411, Bcl-2, and c-MYC), PS5.M and PS2.M dimers were slightly less active than their corresponding monomers (Figure 2D,E and Figure 3A). The initial rate values determined for PS5.M monomer $(365 \mathrm{nM} / \mathrm{s})$ and dimer $(333 \mathrm{nM} / \mathrm{s})$ were similar, an indication that dimerisation of this aptamer did not have a synergistic effect on activity. Furthermore, the initial rate value determined for the trimer $(597 \mathrm{nM} / \mathrm{s})$ is about 1.5 -fold higher than that of the monomer. Rather than having a rate-enhancing effect, these results suggest that multimerisation resulted in reduced activity per haem binding site in PS5.M. Similar effects were seen in the activities of PS2.M constructs. The dimer was $20 \%$ less active than the monomer, while the activity of the trimer $(485 \mathrm{nM} / \mathrm{s})$ was about $16 \%$ higher than that of the monomer $(416 \mathrm{nM} / \mathrm{s})$ (Figure $3 \mathrm{~A})$.

\subsection{AS1411 Multimers Display High Activities at Low DNAzyme Concentrations}

The results presented above (Figures 2 and 3) show that AS1411 DNAzymes were generally more active than the other aptamers tested in this study. The high activity seen with AS1411 trimer indicates that this construct could be the starting point for further optimisation experiments aimed at designing more active aptamers. From a catalytic perspective, it is desirable to have DNAzymes that display high activities at low concentrations, i.e., those with high turnover per unit catalyst concentration.

We compared the activities of AS1411 monomer, dimer and trimer in reactions that contained 0.1, 0.25, 0.5 and $1.0 \mu \mathrm{M}$ DNAzyme concentrations. We included PS5.M for comparison with the AS1411 constructs since it is one of the most studied high activity DNAzymes reported to date. The results (Figure 4) show that all four DNAzymes are active at lower concentrations, and that there is a linear relationship between DNAzyme concentration and ABTS oxidation activity. At $0.1 \mu \mathrm{M}$, the lowest concentration studied, the initial rate for AS1411 trimer was $139 \mathrm{nM} / \mathrm{s}$, which was approximately 4.5 times the value for PS5.M $(31 \mathrm{nM} / \mathrm{s})$ at the same DNAzyme concentration. The high activity of AS1411 trimer at nanomolar concentrations could have practical use in applications where low concentrations of the G4/Hemin DNAzyme are desirable.

\subsection{Effects of Reactants' Concentrations on Activities of AS1411 Multimers}

To further understand the properties of the highly active AS1411 multimers, we examined the effects of ABTS and $\mathrm{H}_{2} \mathrm{O}_{2}$ concentrations on the activities of the DNAzymes. We chose a range of ABTS and $\mathrm{H}_{2} \mathrm{O}_{2}$ concentrations that will allow us to determine the nature of the relationship between reactant concentration and DNAzyme activities. Assays were carried out in reactions that contained $0.25,0.5,0.75,1.0,1.5,2.0$, and $2.5 \mathrm{mM}$ ABTS, representing a 10-fold increase from the lowest to the highest concentration. The effect of $\mathrm{H}_{2} \mathrm{O}_{2}$ concentration was investigated in reactions that contain $0.106,0.213,0.319,0.425,1.063,2.125,3.188$, and $4.250 \mathrm{mM}$, representing a 40 -fold increase from the lowest to the highest concentration.

The results (Figure 5) show that the rates of DNAzyme reactions are effectively controlled by the concentration of $\mathrm{H}_{2} \mathrm{O}_{2}$ in the reaction mixture. The initial rates remained largely unchanged over a 10-fold increase in ABTS concentration (Figure 5G), an indication that the activities of the DNAzymes do not depend on the concentration of the donor substrate. However, as shown in Figure 5A-C, the amount of reaction product formed, as indicated by the endpoint after $5 \mathrm{~min}$ of reaction, is dependent on the concentration of ABTS. It is observed that the time course curves show complete depletion of the substrate at lower concentrations. The rate of this depletion is faster in the more active multimers. 

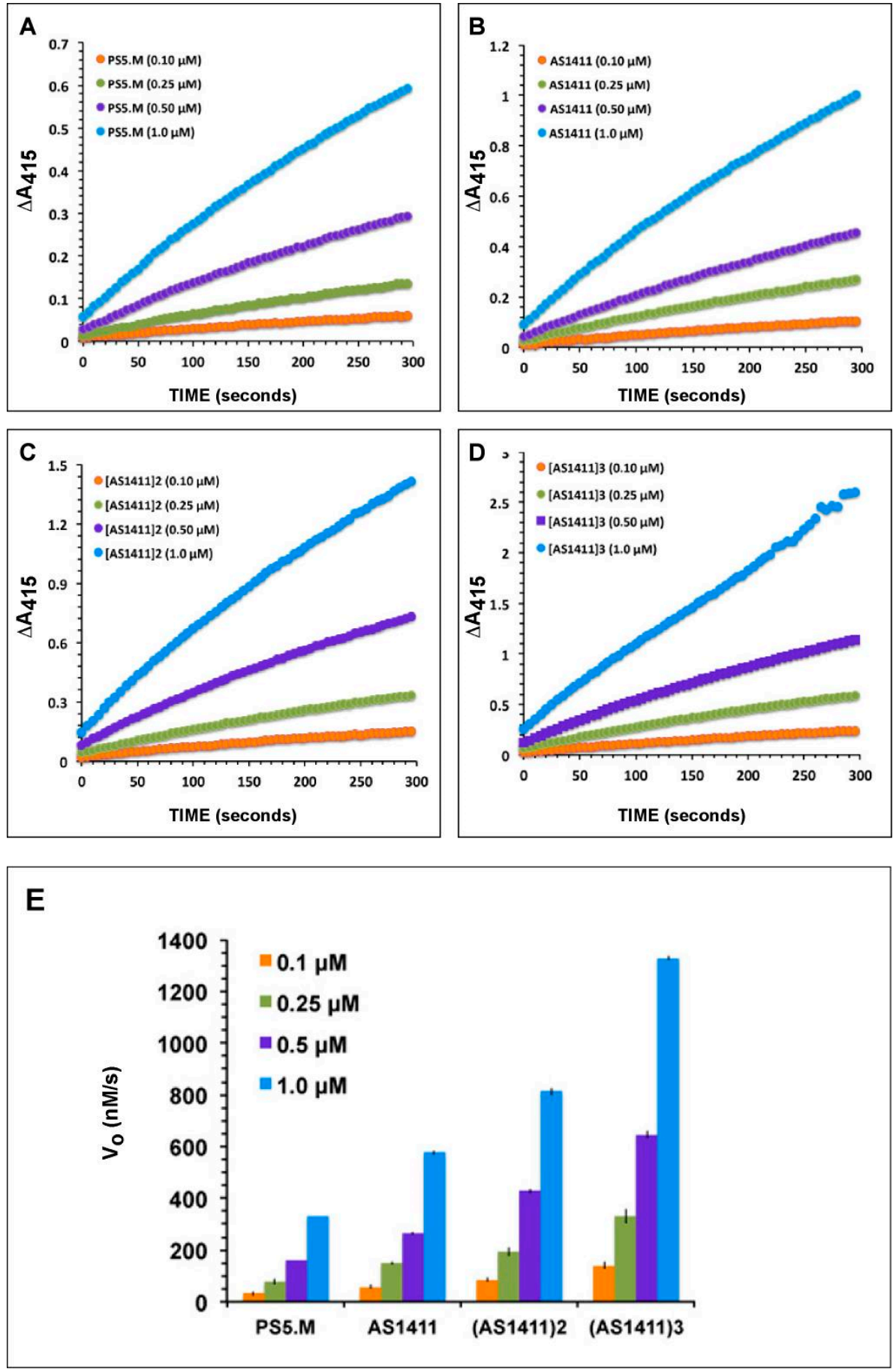

Figure 4. Effect of DNAzyme concentrations on activities of AS1411 multimers and PS5.M. (A) PS5.M; (B) AS1411 monomer; (C) AS1411 dimer; (D) AS1411 trimer. In (A-D), the curves show time courses of ABTS oxidation by $0.1,0.25,0.5$, and $1.0 \mu \mathrm{M}$ DNAzyme. (E) Initial Rates (expressed as $\mathrm{V}_{\mathrm{o}}, \mathrm{nM} / \mathrm{s}$ ) were calculated from the slope of the initial linear portion of the curves shown in (A-D). 

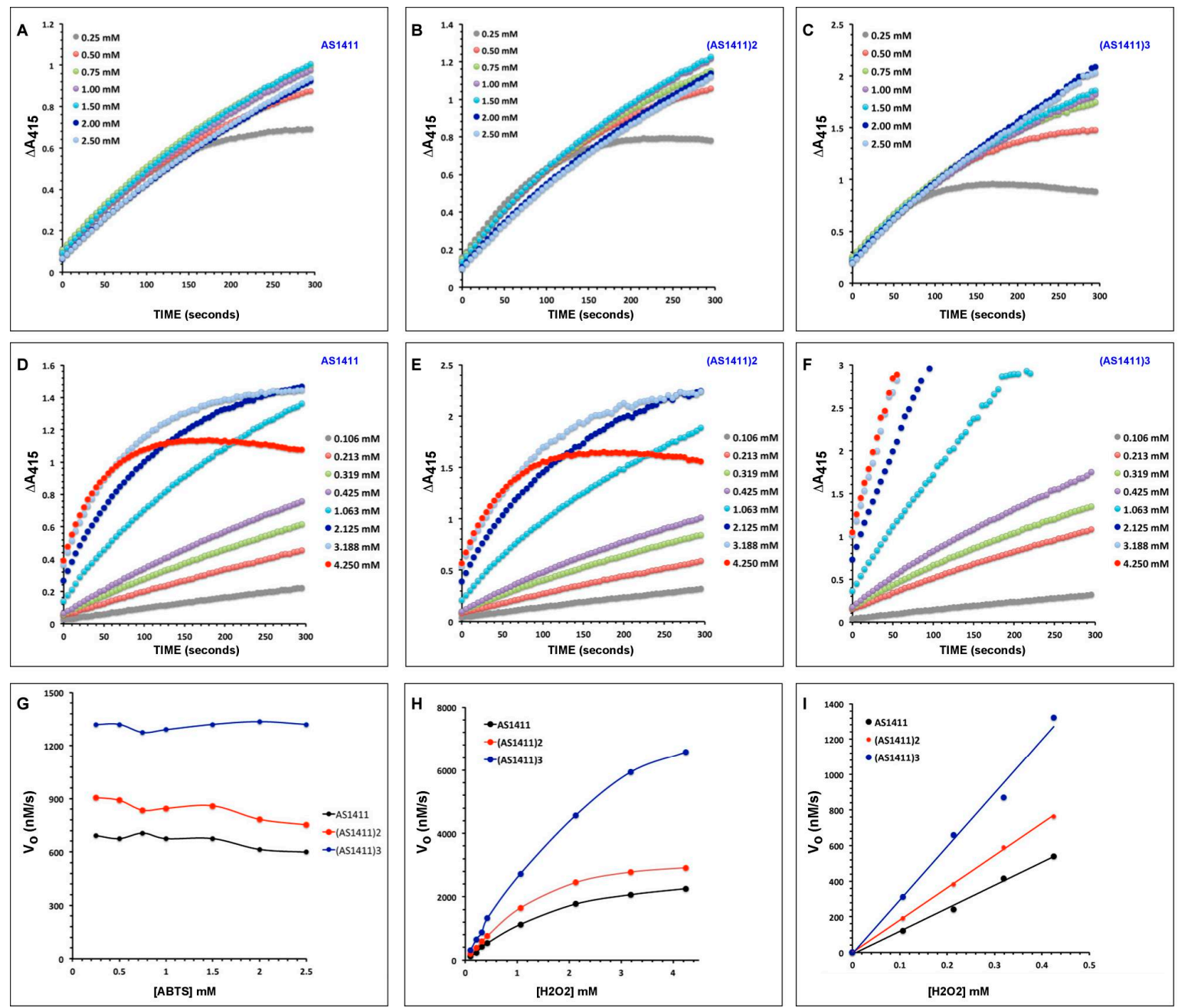

Figure 5. Effects of ABTS and $\mathrm{H}_{2} \mathrm{O}_{2}$ concentrations on activities of AS1411 multimers. The effects of ABTS concentrations on the time course of DNAzyme activities are shown in Panels (A-C). The final ABTS concentrations in the reaction mixtures are $0.25,0.5,0.75,1.0,1.5,2.0$, and $2.5 \mathrm{mM}$. Reactions were carried out at a fixed $\mathrm{H}_{2} \mathrm{O}_{2}$ concentration $(0.425 \mathrm{mM})$, and $1.0 \mu \mathrm{M}$ DNAzyme. Similarly, Panels (D-F) show the effects of $\mathrm{H}_{2} \mathrm{O}_{2}$ concentrations on the time course of reactions at a fixed ABTS concentration (2.5 mM), and $1.0 \mu \mathrm{M}$ DNAzyme. The final $\mathrm{H}_{2} \mathrm{O}_{2}$ concentrations are $0.106,0.213,0.319,0.425,1.063$, $2.125,3.188$, and $4.250 \mathrm{mM}$. The relationship between substrate concentrations and Initial Rates are shown in Panel (G) (ABTS) and Panel (H) $\left(\mathrm{H}_{2} \mathrm{O}_{2}\right)$. Panel (I) shows the linear relationship between Initial Rates and $\mathrm{H}_{2} \mathrm{O}_{2}$ concentration at lower concentrations of the reactant $(0.106,0.213,0.319$, and $0.425 \mathrm{mM}$ ). Initial Rates (expressed as $\mathrm{V}_{\mathrm{o}}, \mathrm{nM} / \mathrm{s}$ ) were calculated from the slope of the initial linear portion of the curves in (A-F).

In contrast to the effect of ABTS concentration, results shown in Figure 5D,E indicate that the initial rates of the three DNAzymes are dependent on the concentration of $\mathrm{H}_{2} \mathrm{O}_{2}$. Figure $5 \mathrm{H}$ shows the dependence of initial rates on $\mathrm{H}_{2} \mathrm{O}_{2}$ concentration. The pattern indicates a linear correlation between $\mathrm{H}_{2} \mathrm{O}_{2}$ concentration and initial rates at the lower $\mathrm{H}_{2} \mathrm{O}_{2}$ concentration (Figure 5I). The trend changed to what appears at first to be a saturation kinetics at higher $\mathrm{H}_{2} \mathrm{O}_{2}$ concentration, especially with AS1411 and (AS1411)2. However, the time course of the reactions at high $\mathrm{H}_{2} \mathrm{O}_{2}$ concentrations (over $2 \mathrm{mM}$ ) shows an early plateau of activity, an indication of inactivation of the DNAzymes at high oxidant concentration. Suicide inactivation of natural protein peroxidases and G-quadruplex peroxidase DNAzymes at high $\mathrm{H}_{2} \mathrm{O}_{2}$ concentration is a well-known phenomenon that limits the use of peroxidases in certain applications [1,6,8]. In addition, high concentration of $\mathrm{H}_{2} \mathrm{O}_{2}$ is known to 
accelerate the disproportionation of $\mathrm{ABTS}^{\bullet}$ radical cation [23]. The response of the activities of the DNAzymes to changes in ABTS and $\mathrm{H}_{2} \mathrm{O}_{2}$ concentrations observed here has also been reported in a previous study where it was shown that DNAzymes behave differently from HRP, a natural protein peroxidase [23].

Interestingly, the plot of Initial Rates versus $\mathrm{H}_{2} \mathrm{O}_{2}$ concentration (Figure $5 \mathrm{H}$ ) shows that the trimer, (AS141)3, appears to be more resistant to the reduction in activity at high $\mathrm{H}_{2} \mathrm{O}_{2}$ concentration. This could be due to presence of multiple active sites or as a consequence of a more stable structural arrangement that protects the hemin at the reaction centre. This property could make (AS1411) particularly useful in reaction systems that require the use of $\mathrm{H}_{2} \mathrm{O}_{2}$ at high concentrations. Further structural studies will provide more insights into the basis for this stability.

\subsection{Determinants of Rate Enhancement by Multivalent DNAzymes}

The goal in designing multivalent G4/Hemin DNAzymes is to achieve increased catalytic performance. While it is expected that molecular coupling of DNAzyme units as dimers, trimers or tetramers could have synergistic effects by resulting in a single molecule with activity higher than that from the sum of the parts, this may not necessarily be the case. One of the key objectives of this study is to gain an understanding of the factors that determine the outcome of multimerising G-quadruplexes in terms of rate-enhancement or lack of it. The activities of G4/Hemin structures are strongly related to the topological structures formed by the DNA sequence [31].

Generally, DNAzymes with parallel G-quadruplex structures tend to have higher activities than those with antiparallel arrangements. It is suggested that the lower activities of antiparallel structures are due to reduced hemin binding as a result of the steric hindrance caused by protruding loops at their outer G-quartets, while parallel G-quadruplexes have no such constraints [32]. Based on several studies, the activities of the different topological forms of G-quadruplexes follow the pattern: parallel > mixed parallel/antiparallel $>$ antiparallel $[8,17,26]$. The topology of a G-quadruplex sequence depends on the length of the loops that connect two adjacent G-tracts. G-tracts with short loops tend to form parallel structures, while long loops give antiparallel topologies [33,34]. In addition, the nature of cations $\left(\mathrm{Na}^{+}, \mathrm{K}^{+}, \mathrm{Mg}^{2+}, \mathrm{NH}^{4+}\right)$ present in the G-quadruplex structure can determine its topological arrangement [8].

Our results show that the G-quadruplexes that are known to form predominantly parallel structures (AS1411, Bcl-2, and c-MYC) showed increased activity upon multimerisation. AS1411 forms a parallel bimolecular quadruplex structure that consists of four pairs of stacked G-tetrads [25]. Similarly, c-MYC forms a parallel structure $[11,35]$. These parallel structural arrangements favour external stacking of the hemin ligand [36]. Earlier studies using NMR showed that Bcl-2 forms mixed parallel/antiparallel structure [28,29]. More recently, it was shown that Bcl-2 formed intramolecular parallel G4 structures in experiments where $\mathrm{CD}$ spectra were measured in a buffer containing $10 \mathrm{mM}$ $\mathrm{NaH}_{2} \mathrm{PO}_{4} / \mathrm{Na}_{2} \mathrm{HPO}_{4}, 100 \mathrm{mM} \mathrm{KCl}$, and $2 \mathrm{mM} \mathrm{MgCl}_{2}$ [11]. It follows that certain buffer conditions might favour a predominance of parallel G4 arrangements, which could explain the high rate enhancement caused by multimerisation of Bcl-2 aptamers into multivalent unimolecular structures.

In contrast, PS2.M forms mixed parallel/antiparallel structure and its structural state seems to be dependent on the nature of the cation used in inducing the folding of the sequence into the G-quadruplex structure $[3,32,37]$. Hence, it is likely that a tendency toward antiparallel topology may not support favourable binding of hemin thereby explaining the relatively modest rate enhancement in multimeric PS2.M and PS5.M. Further mechanistic studies are required to understand why the multimers of PS2. M and PS5.M behaved differently from those of the parallel topology-forming AS1411, Bcl-2 and c-MYC.

It is anticipated that highly active DNAzymes, such as the ones reported in this study, will have applications in designing highly sensitive sensors based on G-quadruplex peroxidase system. The notably high activities of AS1411 multimers would require detailed mechanistic investigation considering that AS1411 forms intermolecular G4 structures. Detailed spectroscopic and structural 
insights into the basis for the high activities of the multimers could provide valuable information on how to design better DNAzymes. Such studies, which are beyond the scope of the work reported here, will be a focus of our future investigation into the properties and applications of multimeric G4/Hemin DNAzymes.

The effect of multimerisation on Bcl-2 and c-MYC shows that the strategy can be used to enhance the activities of G4/Hemin sequences with low activity but which possess other desirable properties. Certain DNAzymes have been designed for optimal activities in conditions of extreme $\mathrm{pH}$, high temperature or other non-standard conditions $[8,17,19]$.

It is worth noting that a different buffer condition, especially one with a different composition of cations, could yield a result pattern that is different from what we observed in this study. Careful variations in ABTS and $\mathrm{H}_{2} \mathrm{O}_{2}$ concentration as well as the concentration of the DNAzyme could reveal further aspects of the reaction properties of multivalent $\mathrm{G} 4 /$ Hemin structures. Further efforts will focus on how flanking residues, linker length and sequence, and rate-enhancing boosting agents (ATP and polyamines) affect the catalytic properties of multivalent G-quadruplex DNAzymes.

\section{Materials and Methods}

\subsection{Reagents and DNA Oligonucleotides}

HPLC-purified DNA oligonucleotides were purchased from Integrated DNA Technologies, IDT (Leuven, Belgium) without further purification. These were dissolved in TE $(1 \times)$ buffer $\left(10 \mathrm{mM}\right.$ Tris- $\mathrm{HCl} \mathrm{pH} 7.5,0.1 \mathrm{mM}$ EDTA) as $100 \mu \mathrm{M}$ solutions and stored at $-20{ }^{\circ} \mathrm{C}$ when not in use. DNA concentrations were determined using $\mathrm{A}_{260}$ and the molar extinction coefficient calculated for each oligonucleotide according to its base sequence. All reagents and substrates were purchased from Sigma-Aldrich, Dorset, UK, and were of analytical grade. The buffer reagent HEPES (2-[4-(2-hydroxyethyl)-1-piperazinyl]ethanesulfonic acid) was prepared as a $200 \mathrm{mM}$ stock solution and stored at $4{ }^{\circ} \mathrm{C}$. Buffers were prepared freshly each week and stored at $22^{\circ} \mathrm{C}$. The standard peroxidase substrate, ABTS (2,2'-azino-bis(3-ethylbenzothiazoline-6-sulphonic acid) was freshly prepared in water as $50 \mathrm{mM}$ solution, and $\mathrm{H}_{2} \mathrm{O}_{2}$ was prepared freshly daily from a $30 \%$ aqueous stock solution (Sigma-Aldrich, UK).

\subsection{Preparation of $G 4 /$ hemin DNAzyme}

$\mathrm{G} 4 /$ hemin DNAzymes were prepared as $10 \mu \mathrm{M}$ solutions and stored at $-20^{\circ} \mathrm{C}$. Briefly, $50 \mu \mathrm{L}$ of $100 \mu \mathrm{M}$ oligonucleotide solution in TE (1X) was added to $450 \mu \mathrm{L}$ of a buffer that contains $25 \mathrm{mM}$ HEPES-NaOH pH 7.4, $20 \mathrm{mM} \mathrm{KCl,} 200 \mathrm{mM} \mathrm{NaCl}, 0.05 \%$ Triton X-100, 1\% DMSO. The sample was heated at $95{ }^{\circ} \mathrm{C}$ for $10 \mathrm{~min}$, and cooled rapidly by dipping in ice. The sample was left at $22{ }^{\circ} \mathrm{C}$ for $30 \mathrm{~min}$ after which equivalent concentration of hemin was added and mixed thoroughly. The sample was kept at $22^{\circ} \mathrm{C}$ for a further one hour after which it was stored at $-20^{\circ} \mathrm{C}$.

\subsection{Determination of G4/hemin DNAzyme Activity}

The activities of the G4/Hemin DNAzymes were determined in reactions that contained $25 \mathrm{mM}$ HEPES-NaOH pH 7.4, $20 \mathrm{mM} \mathrm{KCl}, 200 \mathrm{mM} \mathrm{NaCl}, 0.05 \%$ Triton X-100, 1\% DMSO, $0.25 \mu \mathrm{M}$ DNAzyme, ABTS $(2.5 \mathrm{mM})$ and $\mathrm{H}_{2} \mathrm{O}_{2}(0.425 \mathrm{mM})$. Each reaction was started by the addition of $\mathrm{H}_{2} \mathrm{O}_{2}$, and change in $\mathrm{A}_{415}$ (characteristic for the reaction product $\mathrm{ABTS}^{\bullet}$ ) was monitored immediately after starting the reaction over $5 \mathrm{~min}$ on a CLARIOstar Plate Reader (BMG LABTECH). Absorbance changes were converted to the amount of ABTS ${ }^{\bullet}$ formed using a molar extinction coefficient of $36000 \mathrm{M}^{-1} \mathrm{~cm}^{-1}$ for ABTS ${ }^{\bullet}$ [38]. The initial reaction rate, $\mathrm{V}_{\mathrm{o}}$, expressed as $\mathrm{nM} / \mathrm{s}$, and the amount of ABTS ${ }^{\bullet}$ formed after $5 \mathrm{~min}$ reaction, expressed as $\mu \mathrm{M}$, were determined from the time course of the reaction. The absorbance intensity at $\lambda=415 \mathrm{~nm}$ (corresponding to the amount of $\mathrm{ABTS}^{\bullet}$ formed) was measured as a function of time. The initial rates $\left(V_{o}\right)$ were calculated from the slope of the initial $(30 \mathrm{~s})$ linear portion of the increase in absorbance $[15,39]$. 


\section{Conclusions}

In this study, we have shown that multimeric G4/Hemin peroxidase DNAzymes derived from parallel-forming G-quadruplexes show synergistic and cooperative catalytic activities when compared to their monomeric units. The striking activity of AS1411 trimer makes it a candidate for further designs with potential applications in sensor technologies and other aspects of biocatalysis. The simple multimeric constructs reported in this study provides the basis for further investigation into how this approach could be used to build more efficient catalytic DNA nanodevices. The evidence from this work suggests that parallel topology-forming G-quadruplexes are more likely to form highly active multimers. However, different linker lengths and additional rate-enhancing features could improve the activities of multimers derived from antiparallel G-quadruplexes. Future studies on kinetic characterisation and structural analyses will provide more insights into how multimeric G4/Hemin systems fold and activate peroxidase catalysis.

Author Contributions: Conceptualisation, F.J.O.; Methodology, F.J.O, R.I.A., A.K.P.; Validation, F.J.O.; Formal Analysis, F.J.O.; Investigation, R.I.A., D.S.O., T.K.R.-S., A.B., A.J.R.; Data Curation, F.J.O.; Writing-Original Draft Preparation, F.J.O.; Writing-Review and Editing, F.J.O., R.I.A., A.A.F., T.K.R.-S.; Visualisation, F.J.O; Supervision, F.J.O., S.O.M.; Project Administration, F.J.O.

Funding: This research was supported by institutional funding from Liverpool John Moores University, Liverpool U.K., and MRC Proximity to Development grant MC_PC_16077.

Conflicts of Interest: The authors declare no conflict of interest.

\section{References}

1. Singh, P.K.; Iqbal, N.; Sirohi, H.V.; Bairagya, H.R.; Kaur, P.; Sharma, S.; Singh, T.P. Structural basis of activation of mammalian heme peroxidases. Prog. Biophys. Mol. Biol. 2018, 133, 49-55. [CrossRef] [PubMed]

2. Li, Y.; Sen, D. A catalytic DNA for porphyrin metallation. Nat. Struct. Biol. 1996, 3, 743-747. [CrossRef] [PubMed]

3. Travascio, P.; Li, Y.; Sen, D. DNA-enhanced peroxidase activity of a DNA aptamer-hemin complex. Chem. Biol. 1998, 5, 505-517. [CrossRef]

4. Kosman, J.; Juskowwiak, B. Peroxidase-mimicking DNAzymes for biosensing applications: A review. Anal. Chim. Acta 2011, 707, 7-17. [CrossRef] [PubMed]

5. Tang, Y.; Ge, B.; Sen, D.; Yu, H.Z. Functional DNA switches: Rational design and electrochemical Signaling. Chem. Soc. Rev. 2014, 43, 518-529. [CrossRef] [PubMed]

6. Silverman, S.K. Catalytic DNA: Scope, applications, and biochemistry of deoxyribozymes. Trends Biochem. Sci. 2010, 41, 595-609. [CrossRef] [PubMed]

7. Pelossof, G.; Tel-Vered, R.; Elbaz, J.; Willner, I. Amplified biosensing using the horseradish peroxidase-mimicking DNAzyme as an electrocatalyst. Anal. Chem. 2010, 82, 4396-4402. [CrossRef]

8. Kong, D.M. Factors influencing the performance of G-quadruplex DNAzyme-based sensors. Methods 2013, 64, 199-204. [CrossRef]

9. Keniry, M.A. A comparison of the association of spermine with duplex and quadruplex DNA by NMR. FEBS Lett. 2003, 542, 153-158. [CrossRef]

10. Fu, Y.; Wang, X.; Zhang, J.; Xiao, Y.; Li, W.; Wang, J. Orderly microaggregates of G-/C-Rich oligonucleotides associated with spermine. Biomacromolecules 2011, 12, 747-756. [CrossRef]

11. Qi, C.; Zhang, N.; Yan, J.; Liu, X.; Bing, T.; Mei, H.; Shangguan, D. Activity enhancement of G-quadruplex/hemin DNAzyme by spermine. RSC Adv. 2014, 4, 1441-1448. [CrossRef]

12. Kong, D.M.; Xu, J.; Shen, H.X. Positive Effects of ATP on G-quadruplex-Hemin DNAzyme-mediated reactions. Anal. Chem. 2010, 82, 6148-6153. [CrossRef]

13. Stefan, L.; Denat, F.; Monchaud, D. Insights into how nucleotide supplements enhance the peroxidase-mimicking DNAzyme activity of the G-quadruplex/hemin system. Nucleic Acids Res. 2012, 40, 8759-8772. [CrossRef]

14. Kosman, J.; Zukowski, K.; Juskowiak, B. Comparison of characteristics and DNAzyme activity of G4/Hemin conjugates obtained via two hemin attachment methods. Molecules 2018, 23, 1400. [CrossRef] 
15. Xiao, L.; Zhou, Z.; Feng, M.; Tong, A.; Xiang, Y. Cationic peptide conjugation enhances the activity of peroxidase-mimicking DNAzymes. Bioconj. Chem. 2016, 27, 621-627. [CrossRef]

16. Chang, T.; Gong, H.; Ding, P.; Liu, X.; Li, W.; Bing, T.; Cao, Z.; Shangguan, D. Activity enhancement of G-quadruplex/Hemin DNAzyme by flanking d(CCC). Chem. Eur. J. 2016, 22, 4015-4021. [CrossRef]

17. Chen, J.; Guo, Y.; Zhou, J.; Ju, H. The effect of Adenine repeats on G-quadruplex/hemin peroxidase mimicking DNAzyme activity. Chem. Eur. J. 2017, 23, 4210-4215. [CrossRef]

18. Li, W.; Li, Y.; Liu, Z.; Lin, B.; Yi, H.; Xu, F.; Nie, Z.; Yao, S. Insight into G-quadruplex-hemin DNAzyme/RNAzyme: Adjacent adenine as the intramolecular species for remarkable enhancement of enzymatic activity. Nucleic Acids Res. 2016, 44, 7373-7384. [CrossRef]

19. Guo, Y.; Chen, J.; Cheng, M.; Monchaud, D.; Zhou, J.; Ju, H. A thermophilic tetramolecular G-quadruplex/Hemin DNAzyme. Angew. Chem. Int. Ed. 2017, 56, 16636-16640. [CrossRef] [PubMed]

20. Stefan, L.; Denat, F.; Monchaud, D. Deciphering the DNAzyme activity of multimeric quadruplexes: Insights into their actual role in the telomerase activity evaluation assay. J. Am. Chem. Soc. 2011, 133, 20405-20415. [CrossRef]

21. Yang, D.K.; Kuo, C.J.; Chen, L.C. Synthetic multivalent DNAzymes for enhanced hydrogen peroxide catalysis and sensitive colorimetric glucose detection. Anal. Chim. Acta 2015, 856, 96-102. [CrossRef]

22. Liu, S.; Xu, N.; Tan, C.; Fang, W.; Tan, Y.; Jiang, Y. A sensitive colorimetric aptasensor based on trivalent peroxidase mimic DNAzyme and magnetic nanoparticles. Anal. Chim. Acta 2018, 1018, 86-93. [CrossRef] [PubMed]

23. Li, T.; Dong, S.; Wang, E. G-Quadruplex aptamers with peroxidase-like DNAzyme functions: Which is the best and how does it work? Chem. Asian J. 2009, 4, 918-922. [CrossRef] [PubMed]

24. Liu, B.; Li, D.; Shang, H. General peroxidase activity of a parallel G-quadruplex-hemin DNAzyme formed by Pu39WT-A mixed G-quadruplex forming sequence in the Bcl-2 P1 promoter. Chem. Cent. J. 2014, 8, 43. [CrossRef] [PubMed]

25. Girvan, A.C.; Teng, Y.; Casson, L.K.; Thomas, S.D.; Juliger, S.; Ball, M.W.; Klein, J.B.; Pierce, W.M., Jr.; Barve, S.S.; Bates, J.P. AGRO100 inhibits activation of nuclear factor- $\mathrm{kB}(\mathrm{NF}-\mathrm{kB})$ by forming a complex with NF-кB essential modulator (NEMO) and nucleolin. Mol. Cancer Ther. 2006, 5, 1790-1799. [CrossRef]

26. Kong, D.M.; Yang, W.; Wu, J.; Li, C.X.; Shen, H.X. Structure-function study of peroxidase-like G-quadruplex-hemin complexes. Analyst 2010, 135, 321-326. [CrossRef] [PubMed]

27. Simonsson, T.; Pecinka, P.; Kubista, M. DNA tetraplex formation in the control region of c-myc. Nucleic Acids Res. 1998, 26, 1167-1172. [CrossRef]

28. Dai, J.; Chen, D.; Jones, R.A.; Hurley, L.H.; Yang, D. NMR solution structure of the major G-quadruplex structure formed in the human BCL2 promoter region. Nucleic Acids Res. 2006, 34, 5133-5144. [CrossRef]

29. Dai, J.; Dexheimer, T.S.; Chen, D.; Carver, M.; Ambrus, A.; Jones, R.A.; Yang, D. An intramolecular G-quadruplex structure with mixed parallel/antiparallel G-strands formed in the human BCL-2 promoter region in solution. J. Am. Chem. Soc. 2006, 128, 1096-1098. [CrossRef]

30. Liu, Z.; He, K.; Li, W.; Liu, X.; Xu, X.; Nie, Z.; Yao, S. DNA G-quadruplex-based assay of enzyme activity. Methods Mol. Biol. 2017, 1500, 133-151.

31. Kwok, C.K.; Merrick, C.J. G-quadruplexes: Prediction, characterization, and biological application. Trends Biotechnol. 2017, 35, 997-1013. [CrossRef]

32. Kosman, J.; Juskowwiak, B. Hemin/G-quadruplex structure and activity alteration induced by magnesium cations. Int. J. Biol. Macromol. 2016, 85, 555-564. [CrossRef]

33. Rachwal, P.A.; Brown, T.; Fox, K.R. Effect of G-Tract length on the topology and stability of intramolecular DNA quadruplexes. Biochemistry 2007, 46, 3036-3044. [CrossRef]

34. Bugaut, A.; Balasubramanian, S. A Sequence-independent study of the influence of short loop lengths on the stability and topology of intramolecular DNA G-Quadruplexes. Biochemistry 2008, 47, 689-697. [CrossRef]

35. Phan, A.T.; Modi, Y.S.; Patel, D.J. Propeller-type parallel-stranded G-quadruplexes in the human c-myc promoter. J. Am. Chem. Soc. 2004, 126, 8710-8716. [CrossRef]

36. Li, T.; Shi, L.; Wang, E.; Dong, S. Multifunctional G-quadruplex aptamers and their application to protein detection. Chem. Eur. J. 2009, 15, 1036-1042. [CrossRef]

37. Liu, W.; Zhu, H.; Zheng, B.; Cheng, S.; Fu, Y.; Li, W.; Lau, T.C.; Liang, H. Kinetics and mechanism of G-quadruplex formation and conformational switch in a G-quadruplex of PS2.M induced by $\mathrm{Pb}^{2+}$. Nucleic Acids Res. 2012, 40, 4229-4236. [CrossRef] 
38. Cheng, X.H.; Liu, X.J.; Bing, T.; Cao, Z.H.; Shangguan, D.H. General peroxidase activity of G-quadruplex-Hemin complexes and its application in ligand screening. Biochemistry 2009, 48, 7817-7823. [CrossRef]

39. Nakayama, S.; Wang, J.; Sintim, H.O. DNA-based peroxidation catalyst-what is the exact role of topology on catalysis and is there a special binding site for catalysis? Chemistry 2011, 17, 5691-5698. [CrossRef] 